\title{
Profile of Heavy Metal and Nutrient Elements in Some Sideritis Species
}

\author{
Kürşat Korkmaz $^{1 *}$, Sevket Metin Kara ${ }^{2}$, Faruk Özkutlu', Mehmet Akgün', Belgin Coşge Şenkal ${ }^{3}$ \\ ${ }^{1}$ Department of Soil Science and Plant Nutrition, Faculty of Agriculture, Ordu University, Ordu, TURKEY \\ ${ }^{2}$ Department of Field Crops, Faculty of Agriculture, Ordu University, Ordu, TURKEY \\ ${ }^{3}$ Department of Field Crops, Faculty of Agriculture and Natural Science, Bozok University, Yozgat, TURKEY
}

\begin{abstract}
Background: Medicinal plants are the basic raw material of various herbal formulations in folk medicine in all over the world. In recent years, regarding quality and safety of plant materials collected from different ecological conditions, there has been a growing worldwide interest in monitoring heavy metal contamination and its effect on plant growth and nutrient uptake in medicinal and aromatic plants. Objectives: In this study, profile of heavy metal and selected nutrient elements ( $\mathrm{Il}, \mathrm{Cd}, \mathrm{Co}, \mathrm{Cr}, \mathrm{Ni}, \mathrm{P}, \mathrm{K}, \mathrm{Ca}, \mathrm{S}, \mathrm{Fe}, \mathrm{Cu}, \mathrm{Zn}$, $\mathrm{Mn}, \mathrm{B}$ and $\mathrm{Na}$ ) of three Sideritis species (Sideritis germanicopolitana BORNM, Sideritis galatica BORNM and Sideritis hispida P.H. DAVIS) endemic to Turkey were determined using standard analytical methods. Methods: A scanning ICP-OES (Varian Vista-Pro, Australia) with high-resolution nitrogen purged with $1 \mathrm{~m}$ monochromator was used. Al, $\mathrm{Cd}, \mathrm{Co}, \mathrm{Ni}, \mathrm{Cr}, \mathrm{P}, \mathrm{S}, \mathrm{K}, \mathrm{Ca}, \mathrm{Cu}, \mathrm{Fe}, \mathrm{Mn}, \mathrm{B}, \mathrm{Zn}$ and $\mathrm{Na}$ contents were determined using ICP-OES. Results: The heavy metal and nutrient element concentrations in the Sideritis species were found rather different. Among the three species, Sideritis germanicopolitana showed considerable variation in nutrient concentrations and it was especially rich in iron $\left(365 \mathrm{mg} \mathrm{kg}^{-1}\right)$ and potassium $(2.05 \%)$. The heavy metal concentrations of all Sideritis species, on the other hand, were found to be lower than the permissible limits set aside for human consumption with no health risk in medicinal plants. Conclusions: Sideritis species growing wild in Turkey may be considered to be a crucial source of some nutrients like iron and potassium for human nutrition.
\end{abstract}

Keywords: Herbal tea, Heavy metal, Folk medicine, Medicinal plants, Trace elements.

\section{INTRODUCTION}

Sideritis species have been widely consumed as folk medicine and herbal tea in the world for years. Sideritis L. (Lamiaceae) comprises approximately 150 species of annuals and perennials distributed chiefly in the Mediterranean region. ${ }^{1}$ The genus Sideritis L. is represented in Turkey by 46 species and 53 taxa, 39 of which are endemic and, with $80 \%$ endemism, it has an outstanding feature in flora of Turkey. ${ }^{2,3,4}$ The Sideritis has a widespread usage against gastrointestinal disorders such as stomach ache, indigestion and flatulence, with alleviating the symptoms of common colds including fever, flu, sore throat, and bronchitis as well as a tonic and diuretic remedy. ${ }^{1}$ However, medicinal herb products are neither controlled nor properly regulated by quality assurance parameters. Many medicinal herbs and their mixtures can present a health risk due to the presence of toxic elements such as $\mathrm{Pb}, \mathrm{Cd}, \mathrm{Al}, \mathrm{Hg}$ and other elements like $\mathrm{Cr}$, which are hazardous to humans depending on their oxidation states and concentrations. ${ }^{5,6}$ Therefore, the interest in chemical composition of medicinal herb products is growing because of ongoing developments in nutrition. It is important to have a good quality control for medicinal herbs in order to protect consumers from contamination. ${ }^{6}$ The profile of heavy metal and nutrient elements of Sideritis grown in Tur-
DOI: 10.5530/ijper.51.3s.14 Correspondence: Kürşat Korkmaz, Department of Soil Science and Plant Nutrition, Faculty of Agriculture, Ordu University, Ordu, TURKEY

Contact: +904522347098

E-mail: korkmaz60@odu. edu.tr 
key have not been studied and there are no published reports so far. Therefore, the purpose of this work is to determine the profile of heavy metal and mineral elements of Sideritis germanicopolitana, Sideritis galatica and Sideritis hispida, endemic species used for several purposes in Turkey for years.

\section{MATERIAL METHODS}

Aerial parts of S. germanicopolitana, S. galatica and S. bispida plant samples were collected from nature in Kastamonu, Ankara and Konya provinces of Turkey, respectively, at flowering stage in 2014. The collected plants were dried in shadow at room temperature until they were analyzed. All the plant samples were cleaned and washed with deionized water and air withered. The samples were then withered at $70{ }^{\circ} \mathrm{C}$ for $48 \mathrm{~h}$ in an oven and ground by agate for chemical analysis. The ground materials were stored in polyethylene bottles at room temperature. For chemical analysis, $0.2 \mathrm{~g}$ of each ground sample was put into a burning cup with 5mL HNO3 65\% (Merck, Darmastadt, Germany), and $2 \mathrm{~mL} \mathrm{H}_{2} \mathrm{O}_{2} 30 \%$, (Merck). The samples were incinerated in an HP-500 CEM MARS 5 microwave (Mathews, $\mathrm{NC}$, USA) at $200{ }^{\circ} \mathrm{C}$ and cooled at room temperature for $45 \mathrm{~min}$. The extracts were passed through a Whatman 42 filter paper, and the filtrates were collected by a high deionised water in $20 \mathrm{~mL}$ polyethylene bottles and kept at $4{ }^{\circ} \mathrm{C}$, in the laboratory, for inductively coupled plasma-atomic emission spectrometry (ICP-OES) analysis. Each sample was analyzed in triplicate. Merck standards (R1 and R2 groups) were used as analytical reagent grade chemicals. Standard solutions of $\mathrm{Al}, \mathrm{Cd}$, Co, Ni, Cr, P, S, K, Ca, Cu, Fe, Mn, B, Zn and $\mathrm{Na}$ were prepared in 1\% HNO3 immediately before the analysis by serial dilution of $1000 \mathrm{mg} \mathrm{L}-1$ stock solution stored in polyethylene bottles. Peach leaves (Standard Reference Material, 1547) and corn bran (Standard Reference Material, 8433) were used as reference materials. ${ }^{7}$

A scanning ICP_OES (Varian Vista-Pro, Australia) with high-resolution nitrogen purged with $1 \mathrm{~m}$ monochromator was used. Al, Cd, Co, Ni, Cr, P, S, K, Ca, Cu, Fe, $\mathrm{Mn}, \mathrm{B}, \mathrm{Zn}$ and $\mathrm{Na}$ contents were determined using ICP-OES. In addition, to determine cadmium concentration in the extracts, an inductively coupled argon plasma-optical emission spectrometer (ICP-OES; U-5000AT+ Ultrasonic Nebulizer; Cetac Technologies, Omaha, NE, USA) (214.438 nm/0.1 $\mu \mathrm{gkg}-1)$ was also used. Analytical recovery of the method has been checked by a parallel analysis of the two certified reference materials.

\section{RESULTS AND DISCUSSION}

In this study, the samples of Sideritis species were subjected to chemical analysis for their nutrient elements and heavy metal content. The concentrations of fourteen elements (Al, Cd, Co, Cr, Ni, Ca, K, P, S, Fe, Cu, Mn, $\mathrm{Zn}, \mathrm{B}$ and $\mathrm{Na}$ ) were determined in the plant samples collected. The mean values of heavy metals and selected nutrient elements in Sideritis species obtained from sampling sites were presented in Table 1 and Table 2, respectively.

The heavy metal concentrations were found to be very low in all samples, except for aluminum. The contents of heavy metals were found as; $0.005-0.015 \mathrm{mg} \mathrm{kg}^{-1}$ for cadmium, $0.19-0.52 \mathrm{mg} \mathrm{kg}^{-1}$ for cobalt, $0.41-3.79 \mathrm{mg} \mathrm{kg}^{-1}$ for chrome, $0.61-9.18 \mathrm{mg} \mathrm{kg}^{-1}$ for nickel and 208-418

\section{Table 1: Concentration of Al, Cd, Co, Cr and $\mathrm{Ni}$ in Sideritis species}

\begin{tabular}{|c|c|c|c|c|c|}
\hline & Al & Cd & Co & $\mathrm{Cr}$ & $\mathrm{Ni}$ \\
\hline & \multicolumn{5}{|c|}{  } \\
\hline S. germanicopolitana & 271 & 0.005 & 0.22 & 0.90 & 1.59 \\
\hline S. galatica & 208 & 0.013 & 0.52 & 3.79 & 9.18 \\
\hline S. hispida & 418 & 0.015 & 0.19 & 0.41 & 0.61 \\
\hline
\end{tabular}

${ }^{*} \mathrm{~Pb}$ is below the detection limit.

\section{Table 2: Concentration of $\mathrm{Ca}, \mathrm{K}, \mathrm{P}, \mathrm{S}, \mathrm{Fe}, \mathrm{Cu}, \mathrm{Mn}, \mathrm{Zn}, \mathrm{B}, \mathrm{Na}$ in Sideritis species}

\begin{tabular}{|c|c|c|c|c|c|c|c|c|c|c|}
\hline & $\mathrm{Ca}$ & K & $\mathbf{P}$ & S & $\mathrm{Fe}$ & $\mathrm{Cu}$ & Mn & $\mathrm{Zn}$ & B & $\mathrm{Na}$ \\
\hline & \multicolumn{4}{|c|}{ 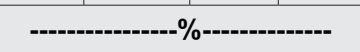 } & \multicolumn{6}{|c|}{ 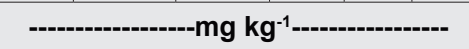 } \\
\hline S. germanicopolitana & 1.24 & 2.05 & 0.22 & 0.18 & 353 & 12.27 & 24 & 33 & 23 & 49 \\
\hline S. galatica & 1.01 & 1.16 & 0.14 & 0.12 & 365 & 8.54 & 22 & 20 & 20 & 42 \\
\hline S. hispida & 1.07 & 1.79 & 0.16 & 0.13 & 254 & 8.34 & 58 & 26 & 20 & 33 \\
\hline
\end{tabular}


mg kg-1 for aluminum. Levels of $\mathrm{Cr}$ and $\mathrm{Ni}$ in $\mathrm{S}$. galatica samples were 4-6 times higher as compared to those of other species. The heavy metals such as $\mathrm{Cd}, \mathrm{Co}, \mathrm{Cr}, \mathrm{Ni}$ and $\mathrm{Pb}$, playing unknown roles in living organisms, are toxic even at very low concentrations. In accordance with the previous studies, the content of $\mathrm{Al}$, known as one of the toxic elements in plants, was high in Sideritis species. ${ }^{5}$ On the other hand, the lowest concentration found was that of chrome followed by nickel, cobalt, and cadmium. The concentration of lead in the samples monitored was below the limit of quantification.

In all samples, the concentrations of heavy metals did not exceed the limits of recommended dietary allowances for medicinal plants. ${ }^{8}$ Heavy metal contents in medicinal plants may show a great variation depending on a variety of factors occurring in plant growing areas. The level of heavy metal content differed in the same medicinal plant collected from environmentally different sites of the same city. ${ }^{9}$ Thus, it was concluded that medicinal plant samples collected from the nature habitat should be tested for contaminant load before processing it further for medicinal use. The level of cadmium in $S$. galatica was found to be as $0.007 \mathrm{mg} \mathrm{kg}^{-1}$, well below the levels established as toxic for human consumption, in samples sold in wholesalers in southeastern Turkey. ${ }^{10}$ In a study ${ }^{11}$ with $S$. galatica collected from the nature during flowering stage, the levels of $\mathrm{Cd}$, $\mathrm{Co}, \mathrm{Ni}, \mathrm{Pb}$ and $\mathrm{Cr}$ were found to be higher than those of the present study.

In the case of micronutrients, the values for boron and copper content in monitored plant samples showed the lowest variation. Of the monitored trace elements, the highest concentration found was that of iron followed by sodium, manganese and zinc. The concentrations of micronutrients were within the ranges of $254-365 \mathrm{mg} \mathrm{kg}^{-1}$ for $\mathrm{Fe}$, 8.34-12.27 $\mathrm{mg} \mathrm{kg}^{-1}$ for $\mathrm{Cu}, 20-33 \mathrm{mg} \mathrm{kg}^{-1}$ for $\mathrm{Zn}, 22-58 \mathrm{mg} \mathrm{kg}^{-1}$ for $\mathrm{Mn}, 20-33 \mathrm{mg} \mathrm{kg}^{-1}$ for B and $33-42 \mathrm{mg} \mathrm{kg}^{-1}$ for $\mathrm{Na}$. It was observed that the macro and micro element values of $S$. germanicopolitana were high, especially those of iron $\left(365 \mathrm{mg} \mathrm{kg}^{-1}\right)$ and potassium $(2.05 \%)$, in comparison with the other species. Thus, S. germanicopolitana appeared to have high nutritional value for human consumption. As $\mathrm{Cu}$ and $\mathrm{Zn}$ are considered micronutrients, the World Health Organization (WHO) limits for these metals have not yet been reported.

The macronutrient $\mathrm{Ca}, \mathrm{K}, \mathrm{P}$ and $\mathrm{S}$ contents of the samples in this study were found to be higher than those of other minerals. The macronutrients $\mathrm{Ca}, \mathrm{K}, \mathrm{P}$ and $\mathrm{S}$ were found to be 1.02 to $1.24 \%$ for $\mathrm{Ca}, 1.17$ to $2.05 \%$ for $\mathrm{K}, 0.14$ to $0.22 \%$ for $\mathrm{P}$ and 0.12 to $0.18 \%$ for $\mathrm{S}$. Our results for certain mineral elements show minor differences when compared with literature., ${ }^{5,11}$ The result of our study agreed with the findings of a previous study, ${ }^{12}$ reporting 3.31-35.1 $\mathrm{mg} \mathrm{kg}^{-1}$ for $\mathrm{Zn}, 1.12-24.4 \mathrm{mg} \mathrm{kg}^{-1}$ for $\mathrm{Cu}, 35.6-241 \mathrm{mg} \mathrm{kg}^{-1}$ for $\mathrm{Fe}, 72.5-685 \mathrm{mg} \mathrm{kg}^{-1}$ for $\mathrm{Mn}, 43.6-613 \mathrm{mg} \mathrm{kg}^{-1}$ for $\mathrm{Na}, 1370-5380 \mathrm{mg} \mathrm{kg}^{-1}$ for $\mathrm{K}$, 2610-51340 $\mathrm{mg} \mathrm{kg}^{-1}$ for Ca and 100-3700 $\mathrm{mg} \mathrm{kg}^{-1}$ for P.

\section{CONCLUSION}

This study attempts to contribute to the knowledge of the nutritional properties of endemic Sideritis species growing wild in Turkey. In addition, the results of the present study revealed that heavy metal contents of Sideritis species from north-western Turkey were within the low ranges, not exceeding the limits of recommended dietary allowances for medicinal plants. On the other hand, mineral nutrient profile obtained in this study suggest that Sideritis species growing wild in Turkey may be considered to be an important source of some nutrients like iron and potassium for human nutrition.

\section{ACKNOWLEDGEMENT}

We would like to thank you Dr. Nazim ŞEKEROĞLU for reviewing the revised manuscript and for efforts on checking English language efficacy.

\section{CONFLICT OF INTEREST}

The author(s) declared no conflicts of interest.

\section{REFERENCES}

1. Gonzalez-Burgos E, Carretero ME, Gomez-Serranillos MP. Sideritis spp. Uses, chemical composition and pharmacological activities -A review. Journal of Ethno pharmacology. 2011:135(2):209-25.

2. Başer $\mathrm{KHC}$, Kırımer N. Bazı yeni bitki türleri ve Türkiye florası için yeni kayıtlar. TAB Bülteni. 1998;(13-4):57-65.

3. Davis PH. Flora of Turkey and the East Aegean Islands, Edinburg University Press, Edinburg. 1988: 10, p.203.

4. Davis PH. Flora of Turkey and the East Aegean Islands, Edinburg University Press, Edinburg. 2000: 11, p.201.

5. Basgel S, Erdemoglu SB. Determination of mineral and trace elements in some medicinal herbs and their infusions consumed in Turkey. Science of the Total Environment. 2006:359(1):82-9.

6. Ozkutlu F, Kara SM, Sekeroglu N. Determination of mineral and trace elements in some spices cultivated in Turkey. In Proceedings of the international symposium on medicinal and nutraceutical plants. Book series. Acta horticulturae. 2007:756;321-7.

7. National Institute of Standards and Technology, Technology Administration, U.S. Department of Commerce, NIST Special Publication. 2004:260-156.

8. A World Health Organization (WHO), Monographs on Selected Medicinal Plants. 1. World Health Organization, Geneva 1999.

9. Barthwal J, Nair S, Kakkar P. Heavy metal accumulation in medicinal plants collected from environmentally different sites. Biomedical and Environmental Sciences. 2008;21(4):319-324.

10. Sekeroglu, N, Ozkutlu, F, Kara, S M, Ozguven, M. Determination of cadmium and selected micronutrients in commonly used and traded medicinal plants in Turkey. Journal of the Science of Food and Agriculture. 2008;88(1):86-90. 
11. Koc H, Sari H. Trace metal contents of some medicinal, aromatic plants and soil samples in the Mediterranean region, Turkey. Journal of Applied Chemical Research. 2009:8:52-7.

12. Ozcan MM, Akbulut M. Estimation of minerals, nitrate and nitrite contents of medicinal and aromatic plants used as spices, condiments and herbal tea. Analytical, Nutritional and Clinical Methods. Food Chemistry. 2007;106(2):852-8.

13. Ajasa AO, Bello MO, Ibrahim AO, Ogunwande IA, Olawore NO. Heavy trace metals and macronutrients status in herbal plants of Nigeria. Food Chemistry. 2004;85(1):67-71.

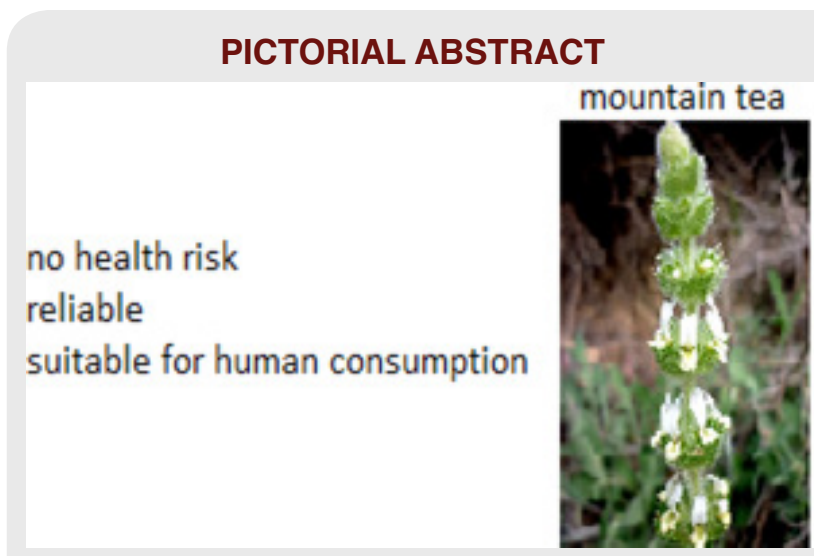

\section{SUMMARY}

- Sideritis germanicopolitana, Sideritis galatica and Sideritis hispida, endemic species used for several purposes in Turkey for years.

- The heavy metal concentrations of Sideritis species were found to be lower than the permissible limits set aside for human consumption with no health risk in medicinal plants.

- Sideritis species growing wild in Turkey may be considered to be a crucial source of some nutrients like iron and potassium for human nutrition.

\section{ABOUT AUTHOR}

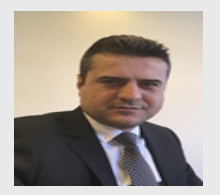

Dr. Kursat KORKMAZ: He is presently working as professor at the Department of soil Science and Plant Nutrition in Ordu University. His studies mainly focused on plant nutrition, plant physiology and medicinal and aromatic plants.

Cite this article: Korkmaz K, Kara SM, Özkutlu F, Akgün M, Cenkal BC. Profile of Heavy Metal and Nutrient Elements in Some Sideritis Species. Indian J of Pharmaceutical Education and Research. 2017;51(3)Suppl:S209-12. 